\title{
Electric Vehicle Adoption in India: A Study Based on System Dynamic Approach
}

\author{
Priyanka Kushwah ${ }^{1 *}$ and Dr. Neha Tomer ${ }^{2}$ \\ 'Research Scholar, School of Business Management, Noida International University, Uttar Pradesh, \\ 203201, India; prynkrthr@yahoo.co.in \\ ${ }^{2}$ Assistant Professor, School of Business Management, Noida International University, Uttar Pradesh, 203201, India
}

\begin{abstract}
The paper studies the adoption of Electric Vehicles (EVs) as an option to do away with Internal Combustion Engine Vehicles (ICEV) which is the major contributors to carbon emissions in today's scenario. The auto-mobile industry is considered responsible for the air pollution due to the fuels derived from the petroleum, which are the source of energy for the internal combustion engine vehicles. Moreover, the prices for fossil fuels are increasing day by day which makes the traditional auto-mobile a costly affair. In order to reduce the vehicular emissions, to gain the energy security, to combat with the rising prices of fossil fuels and to attain environmental sustainability for the coming generations auto-mobile manufacturers and the policy makers around the world are considering electric vehicles as an alternative to internal combustion engine vehicles. Electric Vehicles are being launched as an innovative green product in the market as an alternative to traditional vehicles. The theoretical framework of system dynamics approach have been adopted in the study. Study shows that system dynamics approach is very helpful in understanding policy resistance behaviour of people towards any new initiative. The paper aims to study this policy resistant behaviour of consumers and automotive manufacturers towards EV adoption through system dynamics approach.
\end{abstract}

Keywords: Climate Change, Electric Vehicle Adoption, Future of Mobility, Sustainable Mobility, System Dynamics

\section{Introduction}

In the recent years the thought that is worrying the human kind most is the rising levels of pollution worldwide. Electric Vehicles have emerged as one of the probable solutions for this problem. It has been announced by the Indian government that all new cars registered should be electric by 2030 (Rachana Vidhi \& Prasanna Shrivastava, 2018). To achieve this aim government has come up with FAME (faster adoption and Manufacturing of EVs) I \& II schemes. The adoption rate of EVs is very low in India. The important attributes that contribute to the lower adoption of EVs are its high price, lack of infrastructure, lack of awareness about EVs and limited driving ranges (Larson et al., 2014).

The government is making a strong push for green modes of transport. The move is in line with the current government's increased efforts to push sustainable mobility and tackle pollution across the country by discouraging the purchase of petrol and diesel vehicles.

Various government policies which are meant to push electric vehicles are:

i) The government slashed the Goods and Services Tax (GST) on cleaner vehicles from $12 \%$ to $5 \%$.

ii) No permit requirement for battery operated vehicles used for Taxis, Auto-rickshaws.

iii) No registration fee for EVs is proposed.

iv) Tax exemption on purchase of EVs.

v) Policy guideline issued for charging infrastructure at Residential societies and offices and Rate of electricity charge reduced to make it affordable.

vi) Customs duty reduced on all categories of EVs.

${ }^{*}$ Author for correspondence 
vii) Housing and urban affair ministry to amend building code and town planning rules to include provision of Electric Vehicles charging stations in buildings.

viii) Introduction of Scrap Policy for ICEV.

Despite the several efforts taken by the Indian Government, the adoption in the case of EVs is very low as compared to other developing economies. Although we can see the increase in adoption in the year 2020 but still it is very low. The main demand for the EVs in India is coming in the segment of electric two wheelers and three wheelers. At present the majority of the electric vehicle segment (less than $1 \%$ of total vehicle sales) is dominated by electric 2 wheelers (62\%) and electric 3 wheelers (37\%). But there is very low or negligible adoption in case of four wheelers or personal cars. The government of India is trying to convert the vehicles owned by central agencies into EVs for further promoting them.

The paper aims to study the EV adoption in India through system dynamics modelling. The field of system dynamics created at MIT in the 1950s by Jay Forrester, is designed to help us learn about the structure and dynamics of the complex systems in which we are embedded, design high-leverage policies for sustained improvement, and catalyze successful implementation and change (Forrester, 1961; Sterman, 2000). In this paper we try to study the adoption process for EVs in India, through system dynamics approach. The system dynamics approach was adopted for the study because auto-mobile industry is quite complex, it involve a number of different stakeholders which results in feedbacks with different time lags between the responses of each type of user. System dynamics offer a whole system approach to transport planning and with this different perspective the importance of these feedbacks and lagged responses can be demonstrated to policy makers. The holistic approach of system dynamics is well suited to the bunch of problems that is being faced by Indian Auto-mobile industry right now. The transition of the auto-mobile industry from ICEV to EVs will be a major paradigm shift which will change the whole ecosystem of the transport sector and hence a lot of people will get affected by it. In this study our focus is to provide the dynamics of EV adoption in India and the barriers associated with it. Since, there are many variables or factors associated with the EV adoption we preferred the system dynamics approach to explain their relationships.

\section{Literature Review}

Before designing this research paper extensive literature review has been done on consumer adoption theories, factors effecting the adoption of electric vehicles and effect of government schemes on electric vehicle adoption both by consumer and the manufacturer. The most widely used theory in adoption studies is the Diffusion Of Innovation (DOI) theory given by Rogers in 1962. According to DOI the financial incentives given by state for the adoption of any innovative product accepted the adoption of that product. Moreover the mass adoption of any innovation is essential for its diffusion in the society (Rogers EM, 2003).. In the recent times various researches have been conducted to find out the effect of government policies and financial incentives on consumer adoption, manufacturers decision and EV sales growth. In this segment we have tried to highlight some important studies in the field of EV adoption and their findings which are listed below.

The new and upcoming concept of social commerce and internet cars is the future of EVs. The EV adoption will increase in the near future because of the availability of internet cars and it can be explained by system dynamics modelling and fuggy logic (Feng B., 2018).

In the U.S. market growth of EV adoption is mainly caused by rising prices of gasoline and social preferences rather than by implementing public policies; among all policy measures sales tax incentives have the greatest effect on EV adoption (Gallagher et al., 2014).

The deciding factor for the EV adoption varies in the different markets. For the U.S. market, bottleneck is the high vehicle price set by the manufacturer catalysed by high price sensitivity. In Chinese market the main bottleneck is the number of charging stations and the pricing (Kang et al., 2015).

From the end user point of view the EV adoption can be determined through Theory of Planned Behaviour (TPB), which assumes that human decisions are made based upon rational evaluations of stimuli and the possible consequences of decisions (Azjen, 1991). According to the theory, the more a consumer perceives behaviour to be a social norm the more likely he/she intends to perform the behaviour (Azjen, 1991). In the consumer EV adoption research the consumer knowledge about the benefits of driving EVs for environment is the cause of the attitude formation (Lane \& Potter, 2007). 
In consumer EV adoption literature, scholars assert that symbols and self-identity also play significant roles in consumer adoption behaviour and intentions (Skippon \& Garwood, 2011).

Various studies on consumer adoption of EVs have assumed that EVs are Eco-friendly innovative products which have the potential to reduce the environmental problems of the transportation sector (Lane \& Potter, 2007; Egbue \& Long, 2012).

Studies show that EV has distinct properties when compared with Petrol vehicles. EV has zero tail-pipe emissions and noise and low running cost compared to the internal combustion engines. This is because EV uses electricity as a transport energy source. However, the limited driving range and the time to recharge the battery (at the fast charging stations about 20-30 $\mathrm{min}$ ) are currently considered substantial barriers for adoption. Currently, home charging stations are provided with a new EV, but the public charging infrastructure is limited in Western Australia (Fakhra Jabeen et al., 2013).

Millennials present the greatest opportunity, but auto makers will need to cater to specific sub-segments in order to increase EV adoption. The study shows that abrupt change in technology is possible in near future and can create tremendous pressure of sustainability on automobile manufacturers. The adoption of EVs has been slow, despite solid offerings such as Nissan's Leaf and the Tesla Model S. This is due to a number of mitigating factors, such as state regulations, lack of charging infrastructure, and consumer concern over range.

The Indian auto companies are aware of the new opportunities but not embracing them proactively for various reasons (Anshuman et al., 2018).

According to a study conducted on 1000 Indian consumers, they are willing to pay an additional US\$1034 in purchase price to reduce the fast charging time by 1 minute, US\$7-40 to add a kilometre to the driving range of electric vehicle at 200 kilometres, and US\$104-692 to save US\$1 per 100 kilometres in operating cost (Bansal et al., 2021).

\section{Research Methodology}

The current research is descriptive in nature. The data was collected through online questionnaire in the Delhi \& NCR region by 180 respondents who commute to their offices on a daily basis by personal or public transport. The target population was Academicians, Students and Corporate Employees who travelled daily to their offices and colleges. The data was collected during the lock-down period in the months of April and May, 2020. Keeping in mind the conditions and seriousness of the pandemic the survey was done online. Convenience sampling method was used to identify the respondents. Apart from the demographic profile the questions were asked on a likert scale of 1 to 5 , and the respondents were asked to give their views from strongly disagree to strongly agree. The constructs or the variables of the study were identified from the literature review of EV adoption studies. The constructs of the study were Infrastructure for EVs, Total cost of ownership (TCO) of EVs, Environmental Awareness and Product Awareness about EVs. The descriptive statistics of the study was analysed through SPSS.

System dynamics approach is used to study the causality among the factors (Sterman, 2000). System dynamics is defined as a methodology for understanding complex problems which are dynamic and which involve feedback (Forrester, 1961). Once developed, the model improves the ability of management to assess the future impacts of the proposed strategy by developing a management flight simulator (Sterman, 1992). Auto-mobile Industry is a dynamic and a complex system. It comprises of several interrelated complex subsystems. Therefore, using system dynamics to understand the interaction between various elements like the consumers, manufacturers, suppliers and government policies present a clear picture as how the various elements interact in their micro environment.

The data analysis is done with the help of tools used in system dynamics approach that is Causal Loop Diagram (CLD) and Stock Flow Diagram. The software used for system dynamics modelling is Stella architect.

\section{Data Analysis and Interpretation}

The theoretical framework has been developed to understand the process of EV adoption in India on the basis of literature review. The model has been prepared on the basis of the system dynamics concept. The variables affecting the EV adoption are represented by Causal Loop Diagram. 


\subsection{Causal Loop Diagram}

The various variables affecting the EV adoption have been discussed in the previous section and their effect on behavioural intention was determined through the descriptive statistics of the survey. The items having the strong co-relation were accordingly put into the CLD (Figure 1). According to CLD the variables which are affecting each other in a positive manner are connected by arrows indicating + sign and the variables which are affecting each other in a negative way are connected by arrows indicating - sign. The CLD is representing the dynamics of the EV adoption and the factors affecting its adoption. From the results of the survey it was clear that infrastructure for EVs, Range Anxiety regarding EVS and fear of safety norms are some of the factors which are inhibiting the EV adoption currently. If these factors are worked upon then they will positively influence the EV adoption and this is the reason why they are connected by positive or reinforcing loops. In the another loop the EV adoption is directly influenced by the cost difference between the EVs and ICEVS, since the purchase price of the EVs is quite high in comparison to the ICEVs the EV adoption is low. There is one more loop in the CLD which is representing that the reason for high cost difference between the EVs and ICEVs is due to lack of research in the field of EVs because it is a new sector and the technology is not that much developed in comparison to traditional vehicles. Moreover, once the EV adoption will increase it will decrease the cost difference between the ICEVs and EVs

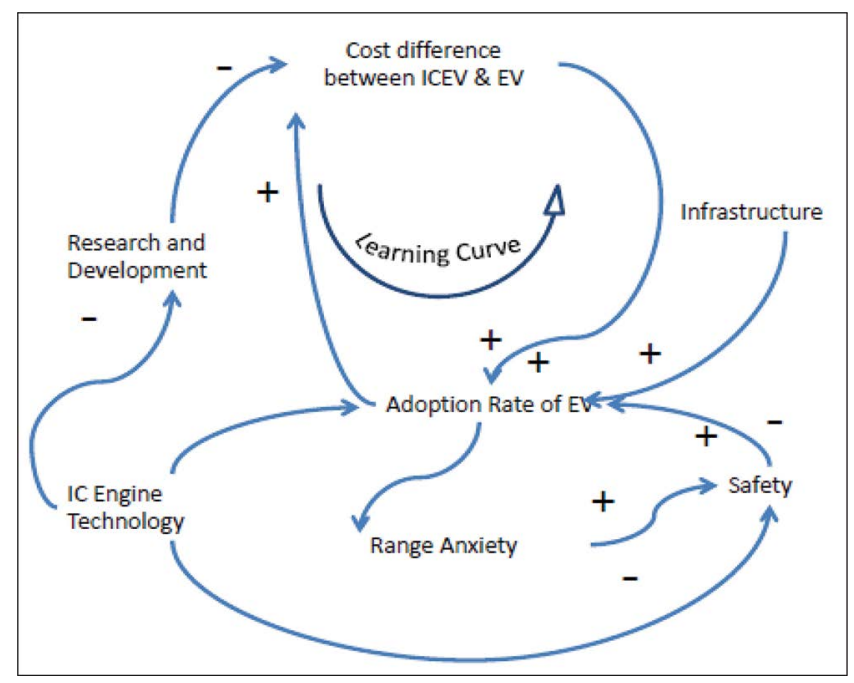

Figure 1. Causal loop diagram. because of mass production hence it is represented by a positive arrow in the CLD. So we can say that the EV adoption is a complex procedure which is being affected by different variables and it can be very well understood by system dynamics approach.

\subsection{Reinforcing and Balancing Loops}

Reinforcing (R) and Balancing (B) loops have been developed to analyse the cause and effect relationship between government policies, Infrastructure for EVs and EV adoption (Figure 2). A positive/reinforcing loop is a causal loop that self-reinforces itself and increases the value of the stock. If the government policies provide the favorable environment for EV adoption, it will increase the number of EV adopters. If the number of EV adopters increase, the EV production will increase and the government will be able to push the cleaner modes of transport. This is a positive reinforcing loop that will continue to benefit both EV adoption and government policies. Environmental Awareness across the globe is increasing and it is forcing all the countries to change their policies for sustainable modes of transport, and these policies in turn are motivating consumers for EV adoption, we have represented this cause and effect in the reinforcing loop.

In the balancing loop we have showed the effect of EV infrastructure and range anxiety on EV adoption. By EV infrastructure we mean the availability of charging stations and facility for EV charging at residential complexes and offices etc. By Range Anxiety we mean the anxiety of the consumer related to the driving range of EVs in the single charge. In the present situation these factors are negatively influencing the EV adoption and hence they are represented through balancing loop.

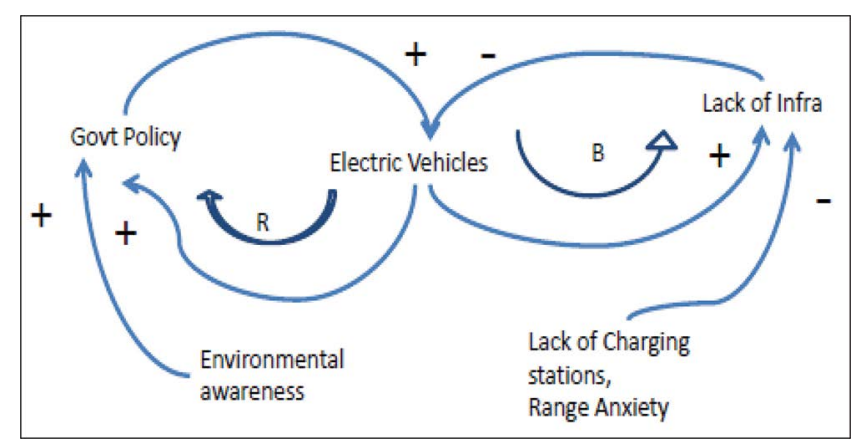

Figure 2. Reinforcing and Balancing loop diagram. 


\section{Conclusion}

The strategic policy issues at a national level involving delays and feedbacks between different systems such as transport have been developed as an area where system dynamics have been relevant. The approach often involves the development of the CLDs. System dynamics should be used to understand and explore the nature of the problem. The system dynamics models can be used to test which parameters play a significant role in the stability and response of the system. The results of this study shows that EV adoption is related to various variables like infrastructure, battery charging stations, range anxiety, the cost difference between EVs and ICEVs, Environmental Awareness and Government Policies. The underlying effects of various interlinked variables that effect the EV adoption is identified and represented using CLD. The model can be used to understand and forecast the determinants of EV adoption in the near future. This paper gives the insight into the topic through system dynamics modelling. The system dynamics model gives more practical approach in solving the real life situations by analysing cause and effect relationships.

\section{References}

1. Ajzen, I. (1991). The theory of planned behavior. Organizational Behav., Human Decision Processes, 50, 179211. https://doi.org/10.1016/0749-5978(91)90020-T.

2. Ankit Kumar, Choudhary, S. K., \& Chethan, K. N. (June 2018). Commercial viability of electric vehicles in India. International Journal of Mechanical Engineering and Technology (IJMET).

3. Bansal Prateek, Kumar Rajeev Ranjan, Raj Alok, Dubey Subodh, \& Graham Daniel. (2021). Willingness to pay and attitudinal preferences of Indian consumers for electric vehicles, Elsevier, 100, 105340. https://doi.org/10.1016/j. eneco.2021.105340

4. Bo Feng, Qiwen Ye, \& Brian J. Collins. (2018). A dynamic model of electric vehicle adoption: The role of social commerce in new transportation, Information \& Management. https://doi.org/10.1016/j.im.2018.05.004.

5. Egbue, Ona \& Long, Suzanna. (2012). Barriers to widespread adoption of electric vehicles: An analysis of consumer attitudes and perceptions. Energy Policy. 48, 717-729. https:// doi.org/10.1016/j.enpol.2012.06.009.

6. Forrester, J. W. (1961). Industrial dynamics, MIT press: Cambridge, MA.
7. Jabeen, Fakhra \& Olaru, Doina \& Smith, Brett \& Braunl, Thomas \& Speidel, Stuart. (2013). Electric Vehicle Battery Charging Behaviour: Findings From A Driver Survey.

8. Kang, N. Ren, Y. Feinberg, F.M., \& Papalambros, P. Y. (2015). Public investment and electric vehicle design: A model-based market analysis framework with application to a USA-China comparison study. Des. Sci., 2(e6). https:// doi.org/10.1017/dsj.2016.7.

9. Lane and Potter. (2007). The adoption of cleaner vehicles in the UK: exploring the consumer attitude-action gap. J. Cleaner Prod.. 15(11-12), 1085-1092. https://doi. org/10.1016/j.jclepro.2006.05.026

10. Mohamed, M., Tamil Arasan G., \& Sivakumar, G. (Feb 2018). Study on electric vehicles in India opportunities and challenges. International Journal of Scientific Research in Environmental Science and Toxicology.

11. Mohd, Sahil Ali, \& Rahul Tongia. (May 2018). Electrifying mobility in India: Future prospects for the electric and EV ecosystem, Brookings India IMPACT Series No. 052018.

12. Morton, C., Anable, J., \& Nelson, J. D. (2017). Consumer structure in the emerging market for electric vehicles: Identifying market segments using cluster analysis. International Journal of Sustainable Transportation, 11(6), 443-459. https://doi.org/10.1080/15568318.2016.1266533.

13. Ning Wang, \& Yafei Liu. (2015). Key Factors Influencing Consumers' Willingness to Purchase Electric Vehicles in China, Research Paper from School of Automotive Studies, Tongji University, Shanghai.

14. Paul, D. Larson, Jairo Viáfara, Robert V. Parsons \& Arne Elias. (2014). Consumer attitudes about electric cars: Pricing analysis and policy implications, Transportation Research Part A: Policy and Practice. 69, 299-314. ISSN 0965-8564

15. Pritam K. Gujarathi, Varsha A. Shah, \& Makarand M. Lokhande. (Jan 2018). Electric vehicles in India: Market analysis with consumer perspective, policies and issues. Journal of Green Engineering.

16. Rachana Vidhi, \& Prasanna Shrivastava. (2018). A review of electric vehicle lifecycle emissions and policy recommendations to increase EV penetration in India, Energies, 11, 483. https://doi.org/10.3390/en11030483.

17. Rogers E. M. (2018). Diffusion of Innovations (5th ed.). Free press: New York.

18. Sharma, R. P., \& Namrata Maheshwari. (2018). A study on the customer"s Awareness and perception level towards green cars. International Journal of Technology Enhancements and Emerging Engineering Research, 2(5).

19. Shikha Juyal, Harkiran Sanjeevi, Abhishek Saxena, Shweta Sharma, Aakaash Singh, Seethapathy Chander, \& Ashok Jhunjhunwala. (2018). NITI Aayog \& World Energy 
Council. Zero Emission Vehicles (ZEVs): Towards a Policy Framework.

20. Skippon, Stephen \& Garwood, Mike. (2011). Responses to battery electric vehicles: UK consumer attitudes and attributions of symbolic meaning following direct experience to reduce psychological distance. Transportation Research Part D-transport and Environment. 16, 525-531. https://doi. org/10.1016/j.trd.2011.05.005.

21. Sterman, J. D. (1992). Teaching takes off: Flight simulators for management education. MS Today (october). Pp. 40-44.

22. Sterman, J.D. (2000). Business Dynamics: System Thinking and Modelling for a Complex World. Irwin Mcgraw-Hill, Boston.
23. Tobias Engelmeier, Nabin Raj Gaihre \& Mohit Anand. (2018). The case for electric mobility in India, TFE Consulting $\mathrm{GmbH}$.

24. Tripathy, Anshuman, Shanker, Bharath and P, Kabilan. (2018). Future of Indian Auto Industry: Choices and Challenges. IIM Bangalore Research Paper No. 566, Available at SSRN: https://ssrn.com/abstract $=3147878$ or http://dx.doi.org/10.2139/ssrn.3147878

25. Zeinab Rezvani, Johan Jansson, \& Jan Bodin. (2015). Advances in consumer electric vehicle adoption research: A review and research agenda. Transportation Research Part D, 34, 122-136. https://doi.org/10.1016/j.trd.2014.10.010. 